\title{
Botulismo de origem alimentar
}

\author{
Foodbourne botulism
}

\section{Natacha Deboni Cereser*I Fernanda Malva Ramos Costa ${ }^{\mathrm{I}}$ Oswaldo Durival Rossi Júnior Décio Adair Rebellatto da Silva' ${ }^{\text {II }}$ Vitor da Rocha Sperotto ${ }^{\text {III }}$}

\section{-REVISÃO BIBLIOGRÁFICA-}

\section{RESUMO}

O botulismo alimentar ocorre pela ingestão de toxinas pré-formadas pelo Clostridium botulinum, consideradas as mais potentes dentre as toxinas conhecidas. Caracteriza-se como uma doença de extrema gravidade, de evolução aguda, provoca distúrbios digestivos e neurológicos, em conseqüência à ingestão de diversos tipos de alimentos. As conservas caseiras estão entre os alimentos que oferecem maior risco à população consumidora. Os produtos de origem animal são frequentemente associados aos surtos da doença, destacandose os embutidos, tais como salsichas, salames, presuntos $e$ patês. Derivados do leite e enlatados, bem como produtos fermentados, são passíveis de provocar a intoxicação. As outras formas naturais da doença são botulismo por feridas $e$ botulismo infantil, normalmente associado ao consumo de mel contendo esporos do Clostridium botulinum.

Palavras-chave: Clostridium botulinum, botulismo alimentar, botulismo infantil.

\section{ABSTRACT}

Foodbourne botulism occurs after ingestion of preformed toxins produced by the Clostridium botulinum, which has been considered one of the most potent known one. The disease, acquired after ingestion of various kinds of foods, has acute character, and provokes gastrointestinal and neurologic symptoms. Homemade canned foods are those that represent higher risk to human health. Processed meat products are frequently associated with botulism outbreaks, mainly sausages, ham and pates. Dairy and canned food, as well as fermented foods, also may be related with this disease. Still, botulism may be caused by toxin production in deep wound, named wound botulism; and after ingestion of honey contaminated with spores by infants, named infant botulism.
Key words: Clostridium botulinum, foodbourne botulism, infant botulism.

\section{INTRODUÇÃO}

O botulismo é uma enfermidade que resulta da ação de uma potente neurotoxina de origem protéica, produzida pelo Clostridium botulinum, normalmente decorrente da ingestão de alimentos, em que a toxina foi previamente elaborada pela bactéria (POLAQUINI et al., 1997; GELLI et al., 2002).

A toxina causa quatro tipos reconhecidos de enfermidades em humanos, incluindo botulismo alimentar, botulismo por feridas, colonização intestinal em adultos e botulismo infantil. $\mathrm{O}$ botulismo alimentar ocorre pela ingestão da toxina pré-formada, enquanto que, nos outros três tipos, a enfermidade ocorre pela infecção, multiplicação e produção de toxinas por microrganismos clostridiais em feridas ou no trato gastrintestinal (CARDOSO et al., 2004; KEET \& STROBER, 2005). A absorção da toxina aerossolizada através do trato respiratório é outra via de intoxicação, mas somente oferece riscos em situações de guerra biológica ou bioterrorismo (FREAN et al., 2004).

O botulismo é uma doença grave, que deve ser considerada emergência médica e de saúde pública. De ocorrência súbita, caracteriza-se por manifestações neurológicas seletivas, de evolução dramática e elevada mortalidade, entre 30 e $65 \%$. É adquirida mais

\footnotetext{
${ }^{\text {I }}$ Departamento de Medicina Veterinária e Reprodução Animal, Faculdade de Ciências Agrárias e Veterinárias, Universidade Estadual Paulista (UNESP), Jaboticabal, SP, Brasil. *Endereço para correspôndencia: CP 031, 98118-000, Boa Vista do Cadeado, RS, Brasil. E-mail: natachacereser@yahoo.com.br ou natacha@fcav.unesp.br.

"I Programa de Pós-graduação em zootecnia, Centro de Ciência Rurais (CCR), Universidade Federal de Santa Maria (UFSM), Santa Maria, RS, Brasil.

IIIDepartamento de Ciências Agrárias, Universidade de Cruz Altal (UNICRUZ), Cruz Alta, RS, Brasil.
} 
comumente, em nosso meio, pela ingestão de alimentos contaminados, tais como embutidos e conservas caseiras que não sofreram tratamento térmico adequado, ou foram armazenados em condições que permitiram a germinação dos esporos do Clostridium botulinum presentes no alimento e a multiplicação do microrganismo, tendo como conseqüência a produção da toxina botulínica.

O botulismo infantil, também conhecido como botulismo de lactentes (associado à Síndrome de Morte Súbita do Recém-Nascido), ocorre em crianças muito jovens devido à absorção de toxina produzida in vivo, no intestino da criança. A ausência da microbiota de proteção permite a germinação de esporos de Clostridium botulinum ingeridos e a produção de toxina na luz intestinal. A doença está normalmente associada ao consumo de mel contaminado, por isso este alimento não deve ser fornecido para crianças menores de dois anos.

\section{Caracterização do agente etiológico}

O Clostridium botulinum é um bacilo gram positivo, que se desenvolve em meio anaeróbio, produtor de esporos, encontrado com freqüência no solo, em legumes, verduras, frutas, sedimentos aquáticos e fezes humanas. $\mathrm{O}$ agente aparece também como habitante normal do trato intestinal de eqüinos, bovinos e aves, onde se multiplica e é excretado em grandes quantidades nas fezes por mais de oito semanas após a primoinfecção (EDUARDO et al., 2002; FREAN et al., 2004).

Os esporos do Clostridium botulinum são as formas mais resistentes que se têm encontrado entre os agentes bacterianos, podendo sobreviver por mais de 30 anos em meio líquido e, provavelmente, mais tempo ainda em estado seco (RADOSTITS et al., 2002). Podem tolerar temperaturas de $100^{\circ} \mathrm{C}$ por horas. Para destruir os esporos, os alimentos contaminados devem ser aquecidos a $120^{\circ} \mathrm{C}$ por 30 minutos. Além disso, os esporos do tipo E são capazes de germinar em temperaturas inferiores a $3^{\circ} \mathrm{C}$ e freqüentemente estão associados com frutos do mar refrigerados (KETCHAM \& GOMEZ, 2003).

A germinação dos esporos nos alimentos é promovida por condições anaeróbicas (alimentos embalados ou lacrados) em que o pH é superior a 4,5, com uma elevada atividade de água. Assim, as células vegetativas produzem a toxina dentro do recipiente durante o armazenamento (SCARCELLI \& PIATTI, 2002).

São descritos sete tipos de Clostridium botulinum (de A a $\mathrm{G}$ ), que se distinguem pelas características antigênicas da neurotoxina que produzem, embora tenham ação farmacológica similar. Assim são conhecidas sete neurotoxinas sorologicamente distintas e altamente potentes (de A a G) (JOHNSON \& BRADSHAW, 2001; JAY, 2005).

Um grama de toxina botulínica é suficiente para matar 30 milhões de camundongos (SCARCELLI \& PIATTI, 2002). A dose letal da toxina botulínica para o ser humano não é conhecida, mas pode ser estimada extrapolando-se os resultados encontrados para primatas. Tem-se, por exemplo, uma dose letal para toxina tipo A em um homem de $70 \mathrm{~kg}$ igual a $0,09-0,15 \mu \mathrm{g}$, por via intravenosa ou intramuscular, de $0,70-0,90 \mu \mathrm{g}$ por inalação, ou ainda de $70 \mu \mathrm{g}$ por via oral (STEPHEN, 2001).

Essas toxinas perdem sua atividade quando submetidas à temperatura de $80^{\circ} \mathrm{C}$ durante 30 minutos ou a $100^{\circ} \mathrm{C}$ por 5 minutos, quando expostas à luz solar por 1 a 3 horas, à temperatura ambiente por 12 horas, ou em 20 minutos em água clorada (destruição de 84\%) (PINILLOS et al., 2003).

Existem diferenças na epidemiologia da intoxicação pelos diferentes tipos de toxinas (FREAN et al., 2004; CARDOSO et al., 2004). As toxinas dos tipos A, B, E e F são as que causam doença humana (a do tipo $\mathrm{G}$ foi associada a alguns casos de morte súbita), enquanto os tipos C e D são quase exclusivos de animais (CARDOSO et al., 2004).

\section{Patogenia}

O botulismo alimentar ocorre quando alimentos que contêm a toxina são ingeridos. Uma vez absorvida, a toxina é transportada via hematógena até neurônios sensíveis (KEET \& STROBER, 2005).

Já o botulismo infantil resulta da ingestão de esporos de Clostridium botulinum presentes nos alimentos. Quando o intestino infantil imaturo é inoculado com esporos e se torna colonizado, como resultado de um elevado $\mathrm{pH}$, falta de ácido biliar e falta de uma microbiota competidora, a toxina botulínica é liberada e prontamente absorvida pela mucosa intestinal. Em 95\% dos casos atinge crianças com três semanas a seis meses de idade (KETCHAM \& GOMEZ, 2003).

As toxinas botulínicas são as mais potentes toxinas conhecidas (GELLI et al., 2002). Estas não atingem o sistema nervoso central devido à barreira hematoencefálica, não ocorrendo, portanto, perturbações de ordem central, permanecendo o paciente, comumente, consciente durante a evolução do quadro (SOUZA, 2001).

As toxinas atuam nas junções neuromusculares, provocando paralisia funcional motora sem a interferência com a função sensorial. Os 
efeitos farmacológicos das toxinas acometem principalmente os nervos periféricos, os quais têm a acetilcolina como mediador. As toxinas ligam-se na membrana nervosa bloqueando a liberação da acetilcolina, causando a paralisia flácida que evolui para a morte, devido à paralisia dos músculos respiratórios, sem o desenvolvimento de lesões histológicas (CDC, 2000; SOUZA, 2001; JOHNSON \& BRADSHAW, 2001).

\section{Ocorrência da doença}

O termo botulismo deriva de "botulus", em latim, salsicha. A história não tem registro sobre casos anteriores a 1793. Neste ano, ocorreu um surto na Alemanha envolvendo 30 pessoas, com seis óbitos, devido ao consumo de "Blunsen", um tipo de salsicha fervida e defumada (SCHOCKEN-ITURRINO, 1980). Em 1897, na Bélgica, investigando um surto de 24 casos, relacionado ao consumo de presunto num funeral, Emile Van Ermangem isolou o microrganismo Clostridium botulinum, detectou sua toxina e determinou que a doença era mediada por esta (KETCHAM \& GOMEZ, 2003).

Segundo GELLI et al. (2002), surtos de botulismo são descritos em todos os continentes. $\mathrm{O}$ número de casos de botulismo e a letalidade têm diminuído devido à utilização do soro antitoxina botulínica, mas esta doença ainda permanece provocando riscos à Saúde Pública (OUAGARI et al., 2002).

EDUARDO et al. (2002) construíram o perfil epidemiológico do botulismo e uma série histórica de casos diagnosticados no Brasil de 1979 até 2002. Nesse período, foram registrados 125 casos, com 75 óbitos, com uma incidência de 5,2 casos/ano e 3,1 óbitos/ano. Dentre os 125 casos, apenas $31(24,8 \%)$ foram notificados, sendo que $79 \%$ ocorreram em 2001 e 2002 , com letalidade de $60 \%$. Destes 31 casos, dois foram por ferimentos e 29 devido a alimento contaminado, sendo cinco por alimentos industrializados, nove episódios por conservas caseiras e dois sem identificação do alimento. Em onze episódios (69\%) foi identificada a toxina tipo A.

No Brasil, o primeiro caso de botulismo notificado à Secretaria de Vigilância em Saúde do Ministério da Saúde ocorreu em 1999 e, até 2004, houve 41 casos suspeitos notificados, sendo confirmado um caso de botulismo por ferimento e 18 casos de botulismo alimentar. Dentre os 19 casos confirmados, a taxa de letalidade foi de $31,6 \%$. Dos casos de botulismo alimentar, 77,8\% foram causados por alimentos de origem suína; $11,1 \%$ por palmito em conserva e, em $11,1 \%$, o alimento não foi identificado. Dos alimentos de origem suína, $85,7 \%$ eram conservas caseiras preparadas com carne suína frita e armazenada em gordura (conhecida como "carne de lata"), $7 \%$ por patê caseiro de fígado suíno e $7 \%$ por lingüiça curada industrializada. A toxina botulínica tipo A foi responsável por $77,8 \%$ dos surtos de botulismo alimentar (EDUARDO et al., 2002).

Apesar de representar uma emergência em Saúde Publica, até 1999, não havia legislação e vigilância da doença no Estado de São Paulo, e, somente em outubro de 2001, tornou-se uma doença de notificação compulsória no Brasil (EDUARDO et al., 2002).

Nos EUA, entre 1899 e 1995 ocorreram 1.026 surtos envolvendo 2.444 pessoas e 1.040 mortes (GELLI et al., 2002). Neste mesmo país, foi relatado ao Center for Diseases Control and Prevention (CDC), em 2001, um total de 169 casos de intoxicação botulínica. Destes, 33 tiveram origem alimentar, ocorrendo uma morte. Foram demonstrados 112 casos de botulismo infantil, 23 casos de botulismo por feridas, e, em um caso, num adulto, ocorreu colonização intestinal e produção de toxina tipo $\mathrm{F}$ (CDC, 2001). Ainda segundo o CDC, $27 \%$ dos casos de botulismo alimentar dos EUA ocorrem no Alaska, devido ao elevado consumo de alimentos fermentados. Entre 1950 e 2000, ocorreram neste Estado 226 casos de botulismo alimentar e todos os casos foram associados ao consumo de alimentos fermentados.

Segundo KETCHAM \& GOMEZ (2003), a incidência anual de botulismo nos EUA é menor que 200 casos. O botulismo alimentar tem uma incidência variável. O botulismo por feridas, que era extremamente raro, agora vem se tornando mais comum, em decorrência do uso de drogas injetáveis. O botulismo infantil é a principal forma de ocorrência naquele país.

Botulismo por alimentos

Os esporos contidos nos alimentos inadequadamente preparados podem germinar e o Clostridium botulinum passar a se multiplicar e produzir toxinas. Inúmeros fatores extrínsecos e intrínsecos podem afetar o desenvolvimento do microrganismo nos alimentos: o Clostridium botulinum não é um bom competidor na presença de outros microrganismos; $\mathrm{pH}$ inferior a 4,5 impede sua multiplicação; atividade de água menor que 0,93 é limitante; concentrações de $\mathrm{NaCl}$ maiores que $8 \%$ impedem a produção da toxina (GELLI et al., 2002). É importante lembrar que nem sempre ocorrem alterações aparentes nos alimentos, como odor, sabor, cor e textura, bem como nem sempre as latas contendo alimentos contaminados estão estufadas (JAY, 2005).

As conservas caseiras constituem o maior risco para o ser humano, em razão dos procedimentos 
inadequados para a preparação dos alimentos. Segundo STEPHEN (2001), nos EUA, inúmeros alimentos têm sido associados aos surtos de botulismo, no entanto, há predominância das conservas de vegetais, especialmente as que apresentam $\mathrm{pH}$ elevado. GELLI et al. (2002) citam que, dos 294 surtos ocorridos nos EUA entre 1973 e 1997, 128 relacionaramse ao consumo de vegetais, 47 de peixes, 16 de carnes, cinco de produtos lácteos, três de comida mexicana e os demais por outros tipos de alimentos, ou não foi possível identificá-los.

$\mathrm{Na}$ Argentina, de acordo com Escartin (2000), citado por GELLI et al. (2002), 16 surtos foram descritos entre 1980 e 1989. Frutas e vegetais foram responsáveis por $36 \%$ dos surtos, 29\% estavam associados ao consumo de carne e $21 \%$ por peixes.

SANTIAGO (1972) relatou a primeira epidemia de botulismo do Brasil, que ocorreu em 1958, no Estado do Rio Grande do Sul, em que nove pessoas morreram após consumirem conserva caseira de peixe.

SERRANO (1982) descreveu um surto de botulismo de origem alimentar, que ocorreu no Estado do Rio de Janeiro em 1982, em que duas pessoas foram acometidas, sendo que uma morreu. O alimento incriminado foi patê de galinha, mantido em condições insatisfatórias de refrigeração.

Um surto de botulismo tipo A ocorreu no Estado de Minas Gerais em 1987, e envolveu sete pessoas de uma mesma família após a ingestão de carne suína conservada sob a forma de enlatado caseiro. Onze meses após, ocorreu um novo caso, e esse episódio passou a ser considerado a segunda epidemia de botulismo ocorrida no Brasil (GELLI et al., 2002).

Segundo EDUARDO et al. (2002), o primeiro caso de botulismo confirmado no Estado de São Paulo ocorreu em 1990, quando uma pessoa desenvolveu a doença após consumir conserva vegetal caseira (picles), que apresentava toxina botulínica tipo A. Posteriormente, entre 1997 e 1999, ocorreram três casos confirmados de botulismo de origem alimentar provocados pela ingestão de conserva de palmito contendo a toxina tipo A. Diante desses casos, a Vigilância Sanitária Nacional determinou a rotulagem de todos os produtos nacionais e estrangeiros, na prateleira e na fábrica, com a advertência ao consumidor para "ferver o produto por 15 minutos antes de ser consumido", pois todo palmito passou a ser considerado suspeito de estar contaminado.

JUNQUEIRA (1994) realizou uma avaliação do risco de transmissão do botulismo pelo consumo de mortadela e presunto. Foram examinadas 100 amostras coletadas no varejo do município de Campinas, Estado de São Paulo. O Número Mais
Provável (NMP) de Clostridium botulinum por $\mathrm{kg}$ de mortadela e presunto foi estimado em $0,27 \mathrm{~kg}^{-1}$ e 0,13 $\mathrm{kg}^{-1}$, respectivamente. A formação de toxina botulínica foi detectada nas amostras de presunto artificialmente contaminadas, após 12 dias de estocagem à temperatura de $30^{\circ} \mathrm{C}$. Ao fim de 28 dias de estocagem, na mesma temperatura, não foi detectada toxina nas amostras de mortadela.

No final de 1996, um surto de botulismo afetou oito jovens na Itália. A investigação epidemiológica levou a suspeitar do queijo cremoso industrializado (Mascarpone) como fonte da toxina botulínica, pois este tinha sido consumido por todos os pacientes antes do início dos sintomas. A toxina do tipo A foi encontrada em algumas amostras de queijo Mascarpone obtidas nas mesmas lojas de varejo em que os pacientes haviam anteriormente comprado os queijos. Uma quebra na cadeia de frio da loja pode ter causado a germinação dos esporos de Clostridium botulinum (AURELI et al., 2000).

Também na Itália, um total de 1.017 amostras de queijo Mascarpone e 260 amostras de outros produtos derivados de leite coletadas no varejo foram analisadas por FRANCIOSA et al. (1999). Os autores pesquisaram esporos e toxina de Clostridium botulinum. Das amostras de queijo, 32,5\% foram positivas para os esporos botulínicos. Dos outros derivados lácteos, $2,7 \%$ foram positivos para esporos do microrganismo. O desenvolvimento e a formação de toxina ocorreram nas amostras de Mascarpone contaminadas naturalmente e experimentalmente após 3 a 4 dias de incubação a $28^{\circ} \mathrm{C}$.

Entre 1993 e 1996, 70 casos foram identificados na França (todas com toxina tipo B). O alimento de maior impacto para a saúde humana foi o presunto (48\%), mas carne de porco cozida, vegetais enlatados e moluscos (mariscos) também foram implicados. Em 50\% dos casos, preparações caseiras em condições precárias foram relatadas (LECLERC et. al., 2002).

CARLIN et al. (2004), também na França, analisaram materiais alimentares crus utilizados na fabricação de produtos refrigerados de longa durabilidade. Estes foram submetidos ao teste de PCRELISA e bioensaio em camundongos para a pesquisa dos tipos A, B e E de Clostridium botulinum. Um total de 7,8\% das 102 amostras de peixes e moluscos; $8,4 \%$ das 143 amostras de carne bovina e de aves; $1,6 \%$ das 62 amostras de molho; $16 \%$ das 25 amostras de material de preenchimento; $11,5 \%$ das 26 amostras de ingredientes lácteos desidratados e nenhuma das 65 amostras de condimentos, ervas e cogumelos desidratados foram positivas para o Clostridium 
botulinum no teste de PCR-ELISA. O número de amostras positivas representou $6,6 \%$ de todas as amostras testadas.

Em 1997, ocorreu nos EUA um caso de botulismo pelo consumo de ovo em conserva. A toxina tipo B foi detectada na amostra do alimento e no soro do paciente (CDC, 2000).

O matambre cozido em água a $78-80^{\circ} \mathrm{C}$ por 4 horas, lacrado em um saco plástico e armazenado em temperatura inadequada, foi o alimento incriminado em um surto de botulismo que acometeu nove pessoas das onze que o consumiram na Argentina. A toxina do tipo A foi identificada nas amostras de soro de três dos nove pacientes. $\mathrm{O}$ tempo de cozimento e temperaturas insuficientes, armazenamento em sacos plásticos e inadequada refrigeração contribuíram para a sobrevivência dos esporos botulínicos, germinação e produção de toxina (VILLAR et al., 1999).

A ocorrência de Clostridium botulinum em amostras de peixes crus (67) e curados (278) em estabelecimentos varejistas de Cochin (Índia) foi estudada. Uma prevalência global de 19\% foi encontrada em peixes crus comercializados. Nas amostras positivas, as toxinas dos tipos de A a D foram detectadas. Em peixes marinhos, a incidência de Clostridium botulinum foi de $18 \%$, enquanto que, em peixes demersais (encontrados em profundidade nos oceanos), $21 \%$ das amostras hospedavam o Clostridium botulinum. A incidência do microrganismo em camarões foi de $25 \%$. Dos 257 peixes curados e testados para o Clostridium botulinum, o nível de contaminação geral foi de $10 \%$. Dentre as toxinas, as dos tipos A a D foram prevalentes nos peixes frescos, e as dos tipos C e D foram as predominantes nos produtos curados. Em camarão salgado desidratado, das 21 amostras analisadas, $10(48 \%)$ hospedavam a toxina botulínica do tipo D (LALITHA \& SURENDRAN, 2002).

Em fevereiro de 2002, dois irmãos sulafricanos, com idades de oito e 12 anos, desenvolveram uma paralisia flácida aguda e morreram. Bioensaios em camundongos revelaram a presença de toxina botulínica do tipo A no soro das duas crianças e nos restos recuperados do alimento implicado. $\mathrm{O}$ veículo implicado da toxina foi peixe enlatado com molho de tomate, comercialmente produzido na África do Sul (FREAN et al., 2004).

OUAGARI et al. (2002) reportaram um estudo epidemiológico e descritivo de onze pacientes que sofreram de botulismo observados pelo Departamento de Doenças Infecciosas da Universidade Ibn Rochd, no Marrocos. O consumo de mortadela foi relatado por sete pacientes e as investigações permitiram identificar a ingestão deste alimento como responsável pela intoxicação.

Charques foram preparados sob condições laboratoriais no sentido de desenvolver experimentos para observar a possibilidade de desenvolvimento de Staphylococcus aureus enterotoxigênico e Clostridium botulinum proteolítico do tipo $\mathrm{B}$ e suas toxinas. Os resultados demonstraram que as condições severas de processamento, elevada concentração de sal, temperatura relativa elevada e baixa atividade de água (aw) inibiram o desenvolvimento de ambas as bactérias. Outro experimento também revelou que a germinação dos esporos de Clostridium botulinum foi prejudicada pelos baixos valores de atividade de água. Sob estas condições, a carne de charque revelou ser um produto seguro em relação à toxina botulínica (LARA et al., 2003).

CARDOSO et al. (2004) descrevem cinco casos de botulismo alimentar em Portugal: três ocorreram de forma isolada e dois casos simultâneos em indivíduos da mesma família. Quatro associaram-se à ingestão de presunto e um à ingestão de atum enlatado.

Um total de 72 casos de botulismo foram registrados na Polônia em 2000. Derivados cárneos foram os principais veículos da toxina botulínica $(56,9 \%)$. Dentre eles, prevaleceram as conservas caseiras preparadas com carne de porco $(18,1 \%)$. Salsichas caseiras estiveram associadas com 13,9\% dos casos, peixe enlatado com $12,5 \%$, salsichas produzidas comercialmente em $12,5 \%$ dos casos e derivados de carne de frango em 11,1\% (PRZYBYLSKA, 2002).

Já no ano de 2002, foram registrados 85 casos de botulismo transmitido por alimentos nesse mesmo país. Os derivados cárneos foram os principais veículos da toxina botulínica ( $68,2 \%$, ou 58 casos), sendo eles conservas caseiras preparadas com carne de porco $(23,5 \%$ dos casos) e salsichas produzidas comercialmente (20\%) os mais comuns (PRZYBYLSKA, 2004).

O botulismo infantil é outra forma importante da doença. No Brasil, no Centro Nacional de Epidemiologia (CENEPI), o Programa de Vigilância do Botulismo iniciou-se em 1999, e, até julho de 2002, 15 casos de botulismo infantil foram notificados (BRASIL, 2002). Nos EUA, desde 1973, uma média de 71 casos de botulismo infantil ocorrem anualmente (SHAPIRO et al., 1998).

Em relação ao botulismo infantil, o alimento mais comumente envolvido é o mel. Pesquisas microbiológicas em todo o mundo têm encontrado esporos de Clostridium botulinum entre 4 e 25\% das 
amostras (KETCHAM \& GOMEZ, 2003; EDUARDO et al., 2002; KEET \& STROBER, 2005). Por conta dessa contaminação e da associação epidemiológica do consumo de mel com o botulismo infantil, a U.S. Food and Drug Administration, o Centers for Disease Control and Prevention e a American Academy of Pediatrics têm advertido que o mel não deve ser administrado a crianças com menos de um ano de idade. De acordo com SHAPIRO et al. (1998), 15\% dos casos de botulismo infantil são provocados pela ingestão de mel contaminado. Nos EUA, MIDURA et al. (1979) isolaram o Clostridium botulinum em nove amostras de mel, das 90 analisadas, sendo seis fornecidas a bebês que desenvolveram a doença.

Em 1996 e 1997, na Argentina, foram avaliadas 45 amostras de mel de 23 marcas comerciais colhidas de colméias principalmente da província de Córdoba. A toxina botulínica e o Clostridium botulinum foram detectados em $7 \%$ das amostras. Uma amostra contendo 15.000 esporos $\mathrm{kg}^{-1}$ foi dada a um bebê que posteriormente desenvolveu botulismo infantil (MONETTO et al., 1999).

CENTORBI et al. (1997), analisando o mel comercializado na Argentina, detectaram esporos do Clostridium botulinum em duas amostras de mel de um total de 177. Naquele mesmo país, FERNANDEZ et al. (1999) descrevem 146 casos de botulismo por toxina tipo A, ocorridos entre os anos de 1982 e 1997. O Clostridium botulinum foi isolado de quatro amostras de mel consumido pelas crianças.

Na Finlândia, um protocolo para a detecção por PCR de esporos de Clostridium botulinum tipos A e B em mel foi desenvolvido e utilizado para a pesquisa de prevalência dos esporos botulínicos em 190 amostras de mel. Esporos do agente foram detectados em $7 \%$ das 114 amostras de mel finlandesas e em 16\% das 76 amostras importadas (NEVAS et al., 2002).

SCHOCKEN-ITURRINO et al. (1999) analisaram 85 amostras de mel comercializado em diferentes Estados do Brasil. Ocorreu multiplicação bacteriana do gênero Clostridium em 23 amostras. Seis foram positivas para o Clostridium botulinum (7,06\%) e identificadas como produtoras de toxinas dos tipos A, B e D. RALL et al. (2003) investigaram a ocorrência de esporos de Clostridium botulinum em 100 amostras de mel comercializado no Estado de São Paulo e encontraram 3\% delas positivas, considerando assim o mel um produto de risco, no que diz respeito ao botulismo infantil. RAGAZANI (2004) avaliou microbiologicamente 100 amostras de mel comercializado no Estado de São Paulo e em outros Estados brasileiros, entre 2002 e 2003. Destas amostras, $39 \%$ apresentaram bactérias sulfito-redutoras. Entre essas, $11 \%$ eram do gênero Clostridium e $7 \%$ foram confirmadas como Clostridium botulinum.

Prevenção

Consiste basicamente em procedimentos capazes de evitar a germinação dos esporos, a multiplicação dos microrganismos e conseqüente produção de toxinas do Clostridium botulinum nos alimentos. Todos os alimentos cujo $\mathrm{pH}$ se situe entre 4,5 e 8,9 e que estejam contidos em embalagens completamente livres de oxigênio são potencialmente botulogênicos. A subesterelização dos alimentos propicia que os esporos do Clostridium botulinum permaneçam viáveis, possibilitando, assim, em condições de sub-refrigeração, a sua germinação, multiplicação bacteriana e produção de toxinas. A esterilização constitui, assim, um fator decisivo para prevenção do botulismo, bem como a conservação dos alimentos em temperaturas de refrigeração ou congelamento.

Os alimentos enlatados cujas latas estejam estufadas devem ser imediatamente rejeitados e destruídos. A educação sanitária da população é fundamental, pois são as conservas caseiras e os alimentos provenientes de estabelecimentos clandestinos os maiores responsáveis pelos surtos de intoxicação botulínica. Além disso, as crianças menores de dois anos não devem consumir mel (BRASIL, 2002).

\section{CONCLUSÃO}

Levando em consideração os dados apresentados, bem como a importância do botulismo como um problema de saúde pública, é indispensável relatar que o maior perigo de contaminação está nos alimentos preparados de forma artesanal, especialmente em conservas caseiras, que são impropriamente manipuladas ou que sofreram tratamento térmico insuficiente para destruir os esporos botulínicos. Além disso, ficou evidente a importância do botulismo infantil, que, em alguns países, representa a maioria dos casos notificados. No entanto, este pode ser facilmente evitado através da conscientização da população quanto ao não-fornecimento de mel para crianças, normalmente as maiores vítimas.

\section{REFERÊNCIAS}

AURELI, P. et al. An outbreak in Italy of botulism associated with a dessert made with Mascarpone cream cheese. European 
Journal of Epidemiology, Roma, v.16, n.10, p.913-918, 2000 .

BRASIL. Ministério da Saúde. Fundação Nacional de Saúde. Guia de vgilância eidemiológica. 5.ed. Brasília: FUNASA, 2002. 842p.

CARDOSO, T. et al. Botulismo alimentar: estudo retrospectivo de cinco casos. ACTA Médica Portuguesa, Lisboa, v.17, p.54-58, 2004.

CARLIN, F. et al. Prevalence of Clostridium botulinum in food raw materials used in Repfeds manufactured in France. International Journal of Food Microbiology, Amsterdan, v. 91, p. 141-145, 2004.

CENTERS FOR DISEASES CONTROL AND PREVENTION/ CDC. Botulism outbreak associated with eating fermented food -Alaska, 2001. CDC, Atlanta, n.32, p.35-39, 2001.

CENTERS FOR DISEASES CONTROL AND PREVENTION/ CDC. Foodborne botulism from eating Home-Pickled Eggs Illinois, 1997. CDC, Atlanta, v.49, n.34, p.57-61, 2000.

CENTORBI, O.P. et al. Detection of Clostridium botulinum spores in honey. Revista Argentina de Microbiologia, Buenos Aires, v.29, n.3, p.147-151, 1997.

EDUARDO, M.B.P. et al. Manual das doenças transmitidas por alimentos e água: Clostridium botulinum/Botulismo. São Paulo: Secretaria de Saúde do Estado de São Paulo, 2002. $41 \mathrm{p}$.

FERNÁNDEZ, R.A. et al. Infant Botulism in Argentina, 19821997. Anaerobe, Los Angeles, v.5, p.177-179, 1999.

FRANCIOSA, G. et al. Clostridium botulinum spores and toxin in mascarpone cheese and other milk products. Journal of Food Protection, Ames, v.62, n.8, p.867-871, 1999.

FREAN, J. et al. Fatal type A botulism in South Africa, 2002. Transactions of the Royal Society of Tropical Medicine and Hygiene, London, v.98, p.290-295, 2004.

GELLI, D.S. et al. Botulism: a laboratory investigation on biological and food samples from cases and outbreaks in Brazil (1982-2001). Revista do Instituto de Medicina Tropical, São Paulo, v.44, n.6, p.321-324, 2002.

JAY, J.M. Microbiologia de alimentos. Porto Alegre: Artmed, 2005. 711p.

JOHNSON, E.A.; BRADSHAW, M. Clostridium botulinum and its neurotoxins: a metabolic and cellular perspective. Toxicon, Oxford, v.39, p.1703-1722, 2001.

JUNQUEIRA, V.C.A. Avaliação da incidência de Clostridium botulinum e da produção de toxina em mortadela e presunto. 1994. 100f. Dissertação (Mestrado em Engenharia de Alimentos) - Universidade Estadual de Campinas.

KEET, C.A.; STROBER, J.B. Recent advances in infant botulism. Pediatric Neuroscience, Basel, v.32, p.149-154, 2005 .
KETCHAM, E.M.; GOMEZ, H.F. Infant botulism: a diagnostic and management challenge pediatric perspective. Air Medical Journal, Orlando, v.22, n.5, p.6-11, 2003.

LALITHA, K.V.; SURENDRAN, P.K. Occurrence of Clostridium botulinum in fresh and cured fish in retail trade in Cochin (India). International Journal of Food Microbiology, Amsterdam, v.72, p.169-174, 2002.

LARA, J.A.F. et al. Evaluation of survival of Staphylococcus aureus and Clostridium botulinum in charqui meat. Meat Science, Barking, v.65, p.609-613, 2003.

LECLERC, V. et al. Pathogens in meat and milk products: surveillance and impact on human health in France. Livestock Production Science, Amsterdam, v.76, p.195-202, 2002.

MIDURA, T.F. et al. Isolation of Clostridium botulinum from honey. Journal of Clinical Microbiology, Washington, v.9, n.2, p.282-283, 1979.

MONETTO, A.M. et al. A study of botulinum spores in honey. Anaerobe, Los Angeles, v.5, p.185-186, 1999.

NEVAS, M. et al. High prevalence of Clostridium botulinum types A and B in honey samples detected by polymerase chain reaction. International Journal of Food Microbiology, Amsterdam, v.30, n.72, p.45-52, 2002.

OUAGARI, Z. et al. Le botulisme à Casablanca. Bulletin de la Societé de Pathologie Exotique, Paris, v.95, n.4, p.272275, 2002 .

PINILlOS, M.A. et al. Intoxicación por alimentos, plantas y setas. Anales del Sistema Sanitário de Navarra, Pamplona, v.26, suppl. 1, p.71-76, 2003.

POLAQUINI, L.E.M. et al. Estudo de toxina botulínica e esporos de Clostridium botulinum em amostras de cama de frangos, coletadas em aviários. In: REUNIÃO DA SOCIEDADE BRASILEIRA DE ZOOTECNIA, 34., 1997, Juiz de Fora, MG. Anais... Juiz de Fora: SBZ, 1997. p.48.

PRZYBYLSKA, A. Botulism in Poland in 2001. Przegl Epidemiologiczny, Warsaw, v. 56, n. 3, p. $305-310,2002$.

PRZYBYLSKA, A. Botulism in Poland in 2002. Przegl Epidemiologiczny, Warsaw, v.58, n.1, p.103-110, 2004.

RADOSTITS, O.M. et al. Clínica veterinária: um tratado de doenças dos bovinos, ovinos, suínos, caprinos e eqüinos. Rio de Janeiro: Guanabara Koogan, 2002. 1737p.

RAGAZANI, A.V.F. Avaliação microbiológica do mel comercializado no estado de São Paulo e outros estados brasileiros. 2004. 76f. Dissertação (Mestrado em Microbiologia) - Faculdade de Ciências Agrárias e Veterinárias, Universidade Estadual Paulista. 
RALL, V.L.M. et al. Honey consumption in the state of São Paulo: a risk to human health? Food Microbiology, London, v.9, p.299-303, 2003.

SANTIAGO, O. Toxi-infecções produzidas por alimentos. Brasília: Departamento Nacional de Inspeção de Produtos de Origem Animal, DIPAC, Ministério da Agricultura, 1972. $276 \mathrm{p}$.

SCARCELLI, E.; PIATTI, R.M. Patógenos emergentes relacionados à contaminação de alimentos de origem animal. Biológico, São Paulo, v.64, n.2, p.123-127, 2002.

SCHOCKEN-ITURRINO, R.P. et al. Study of presence of the spores of Clostridium botulinum in honey in Brazil. FEMS Immunology and Medical Microbiology, Amsterdam, v.24, p.379-382, 1999.

SCHOCKEN-ITURRINO, R.P. Pesquisa de Clostridium botulinum e teste de inoculação em produtos cárneos embalados a vácuo. 1980. 127f. Tese (Doutorado em Engenharia de Alimentos) - Faculdade de Engenharia de Alimentos, Universidade Estadual de Campinas.
SERRANO, A.M. Um provável surto de botulismo humano no Brasil. Higiene Alimentar, São Paulo, v.1 n.2, p.16-19, 1982.

SHAPIRO, R.L. et al. Botulism in the United States: a clinical and epidemiologic review. Annals of Internal Medicine, London, v.129, n.3, p.221-228, 1998.

SOUZA, A.M. Ocorrência de esporos de toxinas de Clostridium botulinum tipos C e D em cacimbas utilizadas como bebedouros de bovinos em pastagens no Vale do Araguaia, Estado de Goiás, Brasil. 2001. 166f. Tese (Doutorado em Medicina Veterinária) - Faculdade de Medicina Veterinária e Zootecnia, Universidade de São Paulo.

STEPHEN, S.A. Botulinum toxin as a biological weapon. Journal of American Medical Association, Chicago, v.285, n. 8, p.43-49, 2001.

VILLAR, R.G. et al. Outbreak of type A botulism and development of a botulism surveillance and antitoxin release system in Argentina. Journal of American Medical Association, Chicago, v.14, n.281, p.1334-1338, 1999. 